\title{
Mind the Gap: The Platform Switching Concept
}

\section{Poojya Ramdev}

\begin{abstract}
After exposing a submerged implant to the oral environment, bone loss occurs downwards along the implant body and stops at some predefined position. A current area of hot debate is the significance of the implant abutment interface and its influence on crestal bone level in relation to the first thread. In recent years, the microgap which exists at the connection between the implant body and the restorative abutment has been implicated. Recently, it has been suggested that the presence and position of the microgap may not be the principal cause of bone resorption phenomenon, but instead that it is due to the relative diameters of the abutment and the implant platform. It appears desirable to incorporate features into implant design which reduce microleakage or limit its effects. A tapered implant abutment creates a microseal and the hermetic seal produced eliminates the microgap preventing the passage of bacteria. Hence platform switching may limit or confine the effect.
\end{abstract}

Keywords: Platform switching, Implant-abutment junction.

How to cite this article: Ramdev P. Mind the Gap: The Platform Switching Concept. Int J Oral Implantol Clin Res 2012;3(3): 130-132.

\section{Source of support: Nil}

Conflict of interest: None declared

\section{INTRODUCTION}

Concept of 'platform switching' refers to the use of a smaller diameter abutment on a larger diameter implant collar. In platform switching it is possible to use abutments with a diameter smaller than the implant neck or body width, or alternatively an implant design can be used in which the neck diameter is increased with respect to the implant body width. A current area of hot debate is the significance of the implant-abutment interface and its influence on crestal bone level in relation to the first thread. In recent years the microgap which exists at the connection between the implant body and the restorative abutment has been implicated.

Antirotational feature on the platform, external hex or within the implant body, internal hex, morse taper, octagon, pin slots, internal grooves increases resistance to occlusal axial loading in implant.

\section{HISTORY}

Wide diameter dental implants in the late 1980, mismatched standard diameter abutments were used. Several early clinical reports demonstrated enhanced tissue responses to these platform switched implants (Figs 1 and 2).

\section{RATIONALE}

Bone resorption at the implant-abutment junction (IAJ) may occur due to inflammatory cell infiltrate that forms a zone

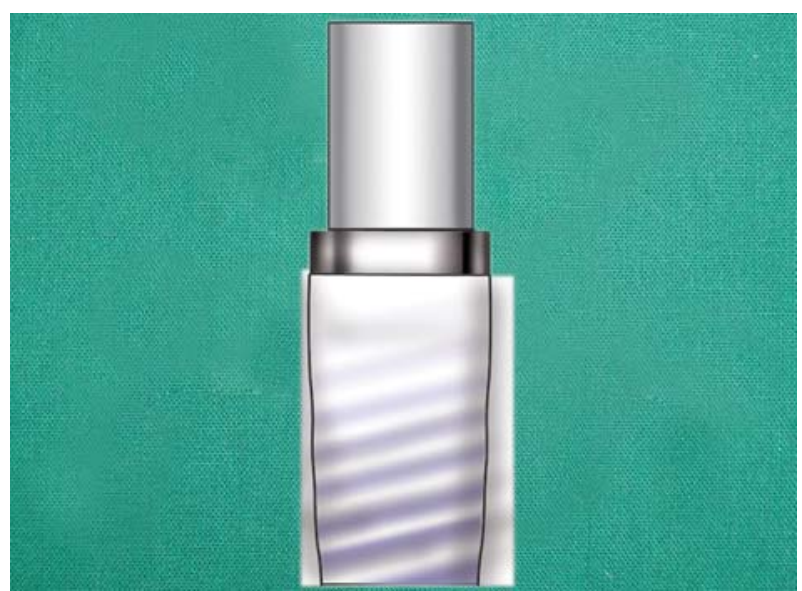

Fig. 1: Platform switched implant with wide diameter implant and narrow abutment

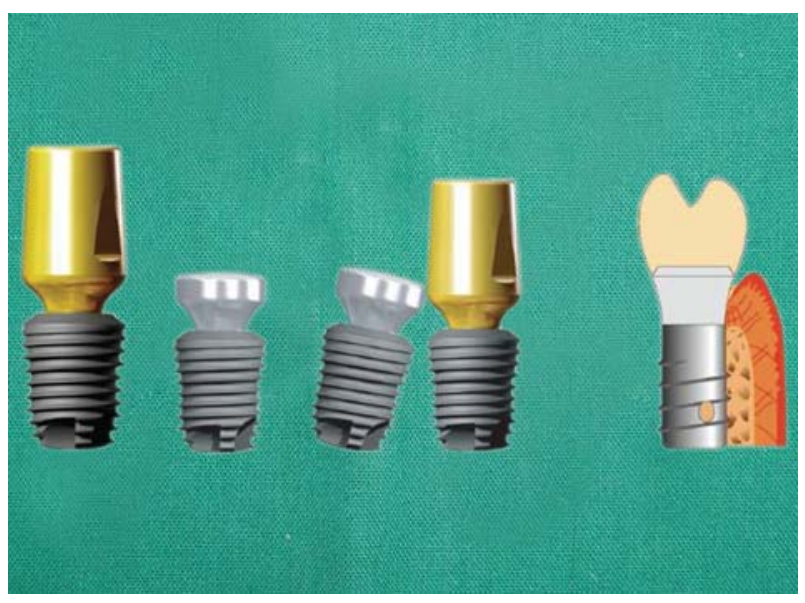

Fig. 2: Platform switched implants

around the IAJ. The current theory of the benefit of platform switching is related to the physical repositioning of the IAJ away from the outer edge of the implant and the surrounding bone, thereby containing the inflammatory infiltrate within the width of the platform switch. The only requirement of platform-switched implant is that the implant should be placed crestally, if sufficient soft tissue height and interocclusal space are present. Soft tissue depth of approximately $3 \mathrm{~mm}$ should be present. Sufficient bone width should be present to accommodate the larger diameter implant.

\section{Significance of the Implant-abutment Interface-Its influence on Crestal Bone Level}

Lazarra and Porter in 2006, based on the studies by Berglundh and Lindhe (1996) and Ericsson et al 1995 hypothesized that the reduced loss of crestal bone is due 
the 'inward repositioning of the implant-abutment interface'. 1

Study on immediate loaded implant with platform switching in the esthetic zone was done and it was concluded that a microrough and nanorough titanium surface extending to the implant shoulder in conjunction with the platformswitching concept provides osseous integration along the entire length of the implant. ${ }^{2}$ A fine thread optimally distributes the masticatory forces in the region of the implant neck, avoiding further bone loss in this region. Reduced crestal bone loss, better force transmission from abutment to implant fixture and superior esthetics was seen.,8

Study was conducted to analyze the effects of the platform switching procedures on stresses in the bone and implant-abutment complex by finite element method (FEM) analysis. Results from this study showed that the platform switching procedure has the biomechanical advantage of shifting the stress concentration area away from the cervical bone-implant interface. The disadvantage of the configuration is the increasing stress in the abutment and IAJ. $^{4}$

\section{Biologic Width Around Implants}

The minimum distance between the abutment-implant interface and bone level has been established as $3 \mathrm{~mm}$ (biologic width of the peri-implant mucosa). It is believed that location of the implant-fixture interface with respect to the crestal bone determines the amount of bone loss occurring to establish the biologic width around implants. The biological space adjacent to an implant is greater than the space adjacent to a natural tooth, with histological differences in terms of the organization and distribution of the fibers. In addition to differences attributable to location, the biological space of an epicrestal implant forms at subcrestal level, while in the case of a natural tooth the space is formed at supracrestal level.

\section{Peri-implant Esthetics}

Platform switching by virtue of preserving the bone at the crest of the implant fixture will contribute to preservation of papillary height between implants and between implant and teeth. Recently, some authors suggested reverse conical neck. Nonsubmerged implant placement makes the microgap far away from the bone.

\section{Comparison of Platform and Nonplatform- Switched Implants}

They found the mean crestal bone loss in platform-switched implants to be $0.22 \mathrm{~mm}$ and it was $2.02 \mathrm{~mm}$ for nonplatformswitched implants. Reduction of the abutment of $0.45 \mathrm{~mm}$ on each side was sufficient to avoid peri-implant bone loss.
The smooth-neck model showed a reduction of stress from 5.6 to $4.9 \%$ after vertical loading and from 3.7 to $2.9 \%$ after oblique loading.

Microthreads increased crestal stress upon loading. Reduced abutment diameter (i.e. platform switching) resulted in less stress translated to the crestal bone in the microthread and smooth-neck groups.

\section{Biomechanical Behavior}

Canay studied a three-dimensional finite elements analysis involving different implant-platform dimensions and a range of abutment designs. ${ }^{4}$ The effect of platform expansion is not attributable to the distribution of loads to the peri-implant bone but rather simply to redistribution of the new biological space, the gingival biotype, the distance of the IAJ from the bone crest, repositioning of the gingival inflammatory infiltrate and the distribution of forces in the portion of the implant in contact with the cortical bone. Additional factors are loss secondary to aggression, such as mucoperiosteal flap raising, second-stage surgery for exposing the screw and colonization by bacteria belonging to the oral flora at the coronal bone and implant junction. Platform expansion in postextraction situations makes it possible to minimize the gap between the recently extracted tooth bed and the implant, acting as a physical barrier against the penetration of bacteria in the zone of contact between the bone and implant. This increase in diameter favors improved primary stability and the formation of a new biological space. The creation of this mechanical barrier serves as a defense mechanism, preventing the penetration of bacteria from the oral environment. In the natural dentition, the junctional epithelium provides a seal at the base of the sulcus against bacterial penetration. The other line of defense present in the natural dentition and absent in implants is the periodontal ligament. Since no cementum or fibers are present on the surface of an implant, infection has the potential to spread directly into the osseous structures resulting in bone loss and ultimately implant failure. Thus, the maintenance of osseointegration and long term success of implants depends on the presence of a leak-proof peri-implant soft tissue cuff.

Trammell et al, in a case-control study, measured the biological space with reduced and conventional platform abutments in the same individual. Although the mean biological width was similar in both groups $(1.57 \pm 0.72 \mathrm{~mm}$ with the expanded platform and $1.53 \pm 0.78 \mathrm{~mm}$ with conventional abutments), bone loss was significantly smaller with the expanded platform. ${ }^{5}$

Study was conducted to biochemically investigate the inflammatory response mediated by Matrix metallo proteinase -8 to platform switching after 3 years of loading. The presence of an implant/abutment mismatching specific for this prosthetic concept is compatible with long-term peri- 
implant health as demonstrated by analysis of a sensitive biomarker of the peri-implant inflammatory response. ${ }^{6}$

\section{Platform Switching-Myth or Fact}

\section{Decrease in Crestal Bone Loss}

High possibility of the deformation in abutment and screw due to the concentrated stress on the junction of abutment and platform.

\section{Provital Platform Switching System}

Platform switching from one implant to another, regardless of the diameter of the implant, healing cap, abutments or any other component elimination of adaptors and additional components.

\section{Production of Custom Tailored Healing Caps or Abutments (Fig. 3)}

The scalloped implant, a design by Noble Perfect, enables the surgeon to place the implant in the residual bone which is characterized by remaining interproximal osseous peaks. The implant is designed such that interproximal peaks of the bone apposition area are in contact with interproximal peaks of the residual bone. It has been found that remodeling in such cases is significantly less when compared with flat prosthetic implant table. $^{7}$

\section{Platform Switching to Maintain Crestal Bone Height}

Shifting the inflammatory cell infiltrate inward and away from the adjacent crestal bone.

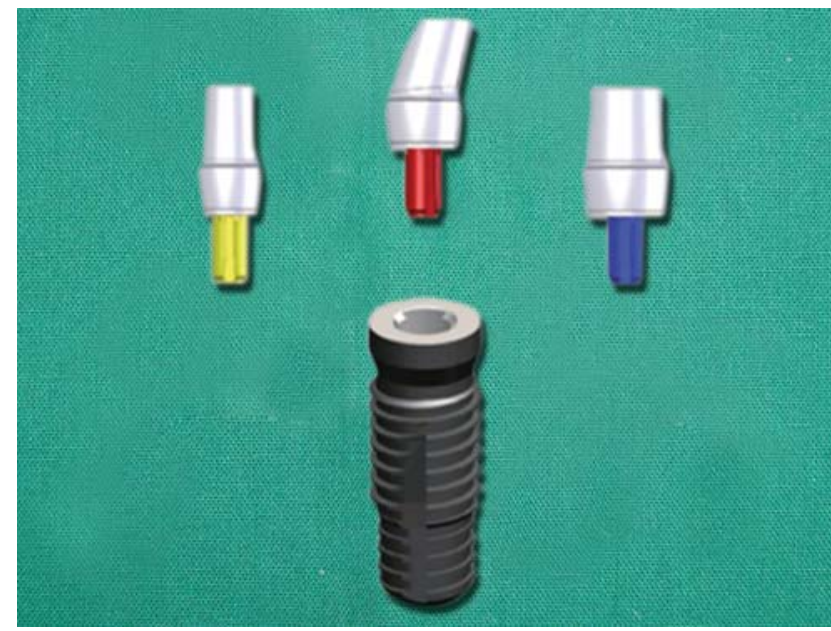

Fig. 3: The Provital platform switching system—custom tailored healing caps or abutments

\section{Maintenance of Biological Width}

The possible influence of microgap on the crestal bone is diminished.

\section{Decreased Stress Levels in the Peri-implant Bone}

Maeda et al, in a three-dimensional finite element analysis, found the biomechanical advantages of platform switching. The use of morse taper connection implants represents a successful procedure for the rehabilitation. ${ }^{4}$

\section{LIMITATIONS}

If normal size abutments are to be used, larger size implants need to be placed. If normal sized implants are placed, smaller diameter abutments are necessary, which may compromise the emergence profile, especially in anterior cases.

\section{REFERENCES}

1. Lazzara RJ, Porter SS. Platform switching: A new concept in implant dentistry for controlling postrestorative crestal bone levels. Int J Periodontics 2006:1:9-17.

2. López-Marí L, Calvo-Guirado JL, Martín-Castellote B, GomezMoreno G, López-Marí M. Implant platform switching concept: An updated review. Med Oral Patol Oral Cir Bucal 2009 Sep 1;14:450-54.

3. Schrotenboer J, Tsao YP, Kinariwala V, Wang HL. Effect of microthreads and platform switching on crestal bone levels: A finite element analysis. J Periodontol 2008 Nov;79(11): 2166-72.

4. Tabata LF, Rocha EP, Barão VA, Assunção WG. Platform switching: Biomechanical evaluation using three-dimensional finite element analysis. Int J Oral Maxillofac Implants 2011;26:482-91.

5. Canullo L, Quaranta A, Teles RP. The microbiota associated with implants restored with platform switching: A preliminary report. J peridontol 2010 Mar;81(3):403-11.

6. Canullo L, Iannello G, Netuschil L, Jepsen S. Platform switching and matrix metalloproteinase-8 levels in peri-implant sulcular fluid. Clin Oral Impl 2011;11:15-18.

7. Prasad DK, Shetty M, Bansal N, Hegde C. Crestal bone preservation: A review of different approaches for successful implant therapy. Indian J Dent Res 2011;22:317-23.

8. Cimen H, Yengin E. Analyzing the effects of platform switching procedures on stresses in the bone and implant-abutment complex by 3-dimensional FEM analysis. J Oral Implantol 2012;38:21-26.

\section{ABOUT THE AUTHOR}

\section{Poojya Ramdev}

Reader, Department of Prosthodontics, MR Ambedkar Dental College and Hospital, Bengaluru, Karnataka, India, Phone: 9886327125 e-mail: rpoojya@yahoo.com 